\title{
PROTOCOL BETWEEN INDIA AND CHINA ON CONFIDENCE BUILDING MEASURES
}

\author{
Protocol between the Government of the Republic of India and the Government \\ of the People's Republic of China on Modalities for the Implementation of \\ Confidence Building Measures in the Military Field along the Line of Actual \\ Control in the India-China Border Areas
}

The Government of the Republic of India and the Government of the People's Republic of China (hereinafter referred to as "the two sides"),

Recalling that both sides are committed to developing their long-term constructive and cooperative partnership on the basis of the Five Principles of Peaceful Coexistence, mutual respect and sensitivity for each other's concerns and aspirations, and equality,

Reaffirming that the two sides seek a fair, reasonable and mutually acceptable settlement of the boundary question,

Reaffirming their commitment that, pending an ultimate solution to the boundary question, both sides shall strictly respect and observe the Line of Actual Control in the India-China border areas,

Noting the utility of confidence building measures already in place along the Line of Actual Control in the India-China border areas,

Recognizing that the maintenance of peace and tranquillity along the Line of Actual Control in the India-China border areas accords with the fundamental interests of the two sides, and will facilitate the process of early clarification and confirmation of the alignment of the Line of Actual Control,

Convinced of the need for agreed modalities for the implementation of confidence building measures between the two sides in the military field along the Line of Actual Control in the India-China border areas, and

Recalling further the relevant provisions of the Agreement on the Maintenance of Peace and Tranquillity along the Line of Actual Control in the India-China Border Areas signed in September 1993 and Agreement on Confidence Building Measures

Asian Yearbook of International Law, Volume 11 (B.S. Chimni et al., eds.)

(C) 2006 Koninklijke Brill NV. Printed in The Netherlands, pp. 351-355. 
in the Military Field along the Line of Actual Control in the India-China Border Areas signed between the two sides in November 1996,

Have agreed on the modalities as follows:

\section{Article I}

In accordance with Article II of the Agreement on Confidence Building Measures in the Military Field along the Line of Actual Control in the India-China Border Areas signed between the two sides in November 1996, the two sides should strictly respect and observe the Line of Actual Control and work together to maintain peace and tranquillity in the border areas.

\section{Article II}

In accordance with Article IV of the Agreement on Confidence Building Measures in the Military Field along the Line of Actual Control in the India-China Border Areas signed between the two sides in November 1996,

(a) Both sides shall avoid holding large-scale military exercises involving more than one Division (approximately 15,000 troops) in close proximity to the Line of Actual Control. However, if such exercises are to be conducted, the strategic direction of the main force involved shall not be towards the other side.

(b) If either side conducts a military exercise involving more than one Brigade Group (approximately 5,000 troops) in close proximity to the Line of Actual Control, it shall not be targeted against the other side. The side undertaking the exercise shall give, through Flag Meetings, the other side prior intimation 15 days in advance of the exercise with regard to type, level, planned duration, and area of exercise as well as the number and type of units or formations participating in the exercise.

(c) Each side shall be entitled to obtain timely clarification within 15 days from the side undertaking the exercise in respect of data specified in paragraph (b) above of the present article, through Flag Meetings. (d) Each side shall give prior intimation of changes in the timing of any scheduled exercise 15 days in advance, through Flag Meetings.

\section{Article III}

In accordance with Article $\mathrm{V}$ of the Agreement on Confidence Building Measures in the Military Field along the Line of Actual Control in the India-China Border Areas signed between the two sides in November 1996,

(a) In the event of an alleged air intrusion of its controlled airspace by the military aircraft of the other side, either side may seek a Flag Meeting within 48 hours of the alleged air intrusion in order to seek a clarification. The investigation shall 
be completed by the other side and its results communicated through a Flag Meeting within a period of four weeks.

(b) If a military aircraft of either side is required to fly across the Line of Actual Control or to overfly the airspace of the other side, prior permission shall be sought from the other side according to procedures and formats to be mutually agreed upon.

(c) If a military or civilian aircraft of either side is required to fly across the Line of Actual Control or to land on the other side of the Line of Actual Control in an emergency situation, the two sides will ensure flight safety in such situations by adhering to procedures to be mutually agreed upon.

\section{Article IV}

In accordance with Article VI of the Agreement on Confidence Building Measures in the Military Field along the Line of Actual Control in the India-China Border Areas signed between the two sides in November 1996, if the border personnel of the two sides come to a face-to-face situation due to differences on the alignment of the Line of Actual Control or any other reason, they shall exercise self-restraint and take all necessary steps to avoid an escalation of the situation. To this end, they shall follow the procedures as given below:

(a) Both sides shall cease their activities in the area, not advance any further, and simultaneously return to their bases.

(b) Both sides shall then inform their respective Headquarters and, if necessary, enter into immediate consultations through border meetings or diplomatic channels so as to prevent an escalation of the situation.

(c) Throughout the face-to-face situation, neither side shall use force or threaten to use force against the other.

(d) Both sides shall treat each other with courtesy and refrain from any provocative actions. Neither side shall put up marks or signs on the spots.

\section{Article V}

In accordance with Article VII of the Agreement on Confidence Building Measures in the Military Field along the Line of Actual Control in India-China Border Areas signed between the two sides in November 1996,

(a) Both sides shall hold two additional border meetings each year at Spanggur Gap in the Western Sector, Nathu La Pass in the Sikkim Sector, and Bum La in the Eastern Sector respectively in celebration of the National Day or Army Day of either side. Specific arrangements shall be decided through consultation between the border forces of the two sides.

(b) Both sides agree in principle to expand the mechanism of border meeting points to include Kibithu-Damai in the Eastern Sector and Lipulekh Pass/Qiang La in 
the Middle Sector. The precise locations of these border meeting points will be decided through mutual consultations.

(c) Both sides shall conduct exchanges between the relevant Military Regions of China and Army Commands of India. Specific arrangements shall be decided upon through mutual consultations between the relevant agencies under the Ministries of Defence of the two sides.

(d) Both sides shall strengthen exchanges between institutions of training of the two armed forces, and conduct exchanges between institutions of sports and culture of the two armed forces. Specific arrangements shall be decided upon through mutual consultations between the relevant agencies under the Ministries of Defence of the two sides.

\section{Article VI}

In accordance with Article VIII of the Agreement on Confidence Building Measures in the Military Field along the Line of Actual Control in the India-China Border Areas signed between the two sides in November 1996,

(a) In the event the personnel of one side in the border areas cross over to the other side due to force majeure such as natural disasters:

i. The side having discovered it should promptly contact and notify the other side;

ii. The personnel crossing over to the other side should, in the light of the prevailing circumstances, take measures to return to their own side or proceed to places designated by the other side en route to return to their own side;

iii. The receiving side will provide all possible assistance to the personnel from the other side and ensure their earliest possible return; and

iv. At the request of the side affected by the natural disaster, the other side may consider all possible measures to help alleviate the situation.

(b) In order to prevent infectious diseases in specific areas on either side in the border areas from spreading to the other side:

i. Both sides should share relevant information promptly through border meetings or diplomatic channels;

ii. Each side should take measures to prevent the spread of diseases from spilling onto the other side; and

iii. At the request of the side suffering from spread of infectious diseases, the other side may consider all possible measures to help alleviate the situation.

\section{Article VII}

The Protocol shall enter into force on the date of signature of this Protocol and will automatically be rendered invalid if the Agreement on Confidence Building Measures in the Military Field along the Line of Actual Control in the India-China Border Areas signed between the two sides in November 1996 ceases to be in force. Subject to 
agreement after mutual consultations between the two sides, the Protocol may be amended and supplemented at any time.

Done in duplicate in New Delhi on 11 April 2005 in the Hindi, Chinese, and English languages, all three texts being equally authentic. In case of any divergence, the English text shall prevail.

For the Government of the Republic of India

For the Government of the People's Republic of China

New Delhi

11 April 2005 